\title{
Commodity Futures: An Important Role in Inventory Management
}

\author{
Dr. John H. Reed, College of Business, Clarion University of Pennsylvania
}

\begin{abstract}
In a production environment costs of raw material inventories can vary dramatically thereby affecting inventory holding costs. Thus savings achieved through the implementation of the results of an EOQ model, which assumes stable inventory costs, may not be applicable where these costs vary. This paper addresses this problem by demonstrating how to integrate the commodity futures markets into an inventory control decision in order to help stabilize the price of inputs.
\end{abstract}

According to Anderson, Sweeney and Williams (1985, p. 429) "the expenses associated with financing and maintaining inventories are a substantial part of the cost of doing business" for some companies. How much and when to replenish inventory is a question that has been extensively analyzed by mathematicians. Models have been constructed which provide guidance to inventory control managers in their attempt to devise inventory operating strategies oriented towards minimization of production costs or maximization of production profits. Some of the models, such as the EOQ model, are quite simple while others are mathematically complex. Many of the models discussed in production texts assume that the cost of materials are constant and when the cost of materials is considered the cost changes are assumed to be predictable, such as price breaks for large orders. However there are many examples of industries in which the cost of inputs fluctuate greatly and unpredictably over time. Consider food processing industries in which it is not unusual for agricultural goods such as wheat, corn, soybeans orange juice, beef and pork to change by as much as fifty percent or more over a three to six month period. Similarly, large and unpredictable price variation is common to lumber and copper which are important components of the construction, furniture and electrical equipment industries. Finally, oil prices have had significant price variation over relatively short time periods. The price of oil is very important to the transportation and electric utility industries.
The application of an inventory control model to discover the optimal order size and order frequency may enable a manufacturer to save as much as ten or twenty percent on inventory costs. While this is a significant amount, such a saving is of little value if in the course of its implementation, the price of the goods in question suddenly increases by fifty percent or more. In such a situation, manufacturers can find themselves in a dilemma because competitive and political forces may make it difficult to pass these increases to their customers. Thus an operational strategy must be devised for the inventory control problem which will enable the decision maker to accommodate the dynamic pricing structure of inventory. There are two possibilities that will enable inventory control models to accommodate changing costs: one, incorporating forecasting techniques into the model, and two, shifting the risk of price changes to a third party. At the present time, most forecasting techniques identify and study the relationships that exist between variables and then assume that the relationships that have existed in the past will continue into the future. Unfortunately, a quick examination of any edition of the Commodity Year Book demonstrates that frequently price changes in raw materials do not adhere to historical patterns. Furthermore, the incorporation of forecasting techniques into inventory control models would tend to make them very complex. Thus if a manufacturer could shift the risk of price changes to a third party, he would be able to continue to use cur- 
The Journal of Applied Business Research - Vol. 6, No. 1

rent inventory control models without concern as to how changing prices would affect the output of these models. A system that permits a party to shift the risk of changing prices to a third party does exist. It is called the commodity futures markets, and the process used to shift risk is called hedging.

A futures contract is an agreement between two parties in which one party agrees to deliver a specific amount of a commodity at a specified price on a specified date in the future to a second party who agrees to take delivery of the commodity. Note that a futures contract does not mean that the subject commodity exists at the time the contract is made. It is only necessary for the commodity to exist at the time of delivery, if and when delivery is required. This important fact means that the money or margin required for the initial investment is low, usually five to ten percent of the value of the contract. The margin is returned to the investor if the contract is profitable. If the contract losses exceed the margin, the investor will be required to add more money. In addition, there is a large secondary market for most commodities traded on the futures markets, and if either party to the contract desires to get out of the agreement, they need only to take a position opposite their initial position. For example, if a buyer of a contract decides he no longer needs the commodity, he can sell the contract to another party who then assumes the responsibilities of the contract. While delivery of a commodities future contract rarely occurs, the threat of delivery causes futures prices to change with the cash price of the commodity.

Production texts do not consider the affect of large and unpredictable price changes of inputs of a manufacturing system or the role that the futures markets can play in this problem. Hedging through the futures markets stabilizes prices by shifting the risk of price change to a third party so that the production manager does not have to worry about how price changes effect the inventory ordering policy. Instead, the production manager is presented with a different but easier problem. What is the price level of inputs with which the company can make a reasonable profit? When this price level is identified, the manager must begin a hedging program to guarantee this price level.
In a manufacturing environment there, are two types of hedging situations:

1. The manufacturer uses large amounts of a raw material which is traded on the futures markets. Examples of these materials would be precious metals, copper, lumber and basic agricultural products such as corn, wheat, soybeans and oats.

2. The manufacturer does not purchase in raw material form a commodity which is traded in the futures market, but does purchase large amounts of a manufactured product in which a major part of its value consists of a material which is traded in the futures market.

To demonstrate the role that the futures markets can play in inventory control, an example of each type of hedging process is presented.

Example I. Situation in which a company uses a large amount of a material which is traded in the futures market.

An inventory control manager for a factory which makes copper wire is planning the copper requirements of the company for the last quarter of the fiscal year which begins on October 1 . It is estimated that the company will need 100,000 pounds of copper for this quarter. Presently, copper is selling for 65 cents a pound. After consulting with the marketing department and the production department, it is determined that the company can make a reasonable profit if the price of copper remains at 65 cents a pound. However, should prices suddenly rise by ten percent or more, profitability would be seriously threatened. Thus the inventory control manager has decided to enter the futures market in order to guarantee the price of copper in October. Four copper contracts are purchased at 25,000 pounds for delivery in September. The price agreed on by the buyer and the seller is 65 cents a pound.

In September, when it is time for settlement, the price of copper has risen to 80 cents a pound, however the delivery point of the copper contracts is Chicago. Since the company is located in a distant city, the inventory control manager decides to cancel the contracts before the delivery date and then purchase the copper locally. The computations are as follow: 
$4 \times .65 \times 25000=65000$ (initial value of 4 contracts)

$.1 \times 65000=6500$ (margin requirements)

$4 \times .80 \times 25000=80000$ (value of 4 contracts in September)

$80000-65000=15000$ (profit from futures transactions)

The cost of purchasing copper locally is $\$ 80000$.

$$
.80 \times 100000=80000
$$

Thus the cost of copper in October will be 65 cents a pound, a price at which the company will earn a reasonable profit.

$80000-15000$ (profit from futures) $=65000$

In this situation had the company not hedged, its profitability would have been threatened.

Now suppose that in September the price of copper had fallen to 50 cents a pound, then the following computations would have been appropriate:

$4 \times .65 \times 25000=65000$ (initial value of 4 contracts)

$.1 \times 65000=6500$ (margin requirements)

$4 \times .50 \times 25000=50000$ (value 4 of contracts in September)

$65000-50000=15000$ (loss from futures)

Thus the company would have been required to pay another 8500 dollars to cover the losses in the futures market.

$15000-6500=8500$

However when the copper is purchased locally, the company must spend only 50000 dollars. Therefore the cost of copper in October is 65 cents a pound, a price with which the company can make a reasonable profit.

$50000+15000=65000$

In this instance, by hedging, the company gave up the chance to make an additional $\$ 15$,000 for a guarantee that the price of copper would not increase by an amount which would threaten its profitability.

Example II. A situation in which a company uses a large amount of a product which is not traded on the futures market, but a major component of the product is traded on the futures market, and time is required for the input to reflect price changes in the hedged raw material.

An inventory control manager for a company that manufactures electric motors makes decisions on large purchases of copper wire. Cost data reveals that approximately 60 percent of the cost of the wire is attributed to the price of copper and 40 percent is due to the cost of capital, labor and transportation. The company needs 100,000 pounds of wire on October 1 and the price of copper is presently 65 cents a pound. The cost of 100000 pounds of wire is $\$ 108000$. The manager knows from past experience that any sudden change in the price of copper requires about two months to be passed along to copper wire. How can the manager protect the company from sudden price changes in copper through the futures market? At this point, the manager must do some research to determine how many futures contracts are needed to hedge the wire purchases. According to Figlewski (1986, pp. 27-34) there are two methods for accomplishing this objective, linear regression and deductively reasoning from the relationships between the raw material and the finished product.

The first set of computations makes use of linear regression. This approach requires that the decision maker collect data on copper prices as well as copper wire prices. Once the data have been collected, linear regression is used to determine the relationship of price changes between copper and copper wire. For this example let it be assumed that a linear regression has been performed and that it indicates that every time a pound of copper changes by one cent a pound, wire changes by .7 cents. If copper is the independent variable and wire the dependent variable then the hedge ratio is .7 and the following formula can be used to compute the number of futures contracts needed by the manager: 
The Journal of Applied Business Research - Vol. 6, No. 1

h Nu/S

where

* $\mathrm{h}$ is the hedge ratio

* $\mathrm{Nu}$ is the number of units of the item hedged

* S size of futures contract.

Therefore

$.7 \times 100000 / 25000=2.8$

The manager will purchase three July copper contracts at 65 cents a pound and then sell them in July.

\section{$3 \times .65 \times 25000=48750$ (initial value of 3 contracts)}

Assume that in July, when the contracts are sold, the price of copper is 80 cents a pound. Then

$3 \times .80 \times 25000=60000$ (value of 3 contracts when sold)

Therefore the company realizes a gain of $\$ 11250$ on the futures market.

$60000-48750=11250$

At the end of September the price of wire has risen to $\$ 117750$ or 9.75 cents a pound (.65 cents for each one cent increase in copper). Thus

$117750-108000=9750$

the loss the manager sustained by waiting until September to make the purchase. Of course this $\$ 9750$ is offset by the $\$ 11250$ profit in the futures market so the hedge not only enabled the company to buy the wire at the original price of $\$ 10800$ but also made the company $\$ 1500$, the difference between money made on the futures market and money lost on the cash market. Unlike Example I, a perfect hedge was not achieved.

If the price of copper had fallen to 50 cents a pound instead of rising to 80 cents a pound, a $\$ 1500$ loss would have occurred. When it is impossible to attain a perfect hedge, a loss or gain may occur depending on the direction of the market and whether the manager over or under hedges. Judgement must be used to de- termine the proper number of contracts when the hedge ratio is a fraction. The manager must also be aware that there is some risk that the price change relationship between copper and wire might not be as indicated by linear regression. This was illustrated in the example when linear regression predicted a .7 cent versus an actual .65 cent a pound change in the price of wire for each one cent change in copper. This is a factor that also must be considered by the hedger in determining the number of futures contracts.

Futures contracts are of relatively short duration so it is not always possible to collect enough data to reliably determine the price change relationship between copper and copper wire. In such a case, the manager must determine the hedge ratio using deduction. Since the data in the original problem revealed that 60 percent of the cost of the wire was due to copper, it would be reasonable to conclude that every time copper rises one cent wire rises .6 cents. Thus:

h Nu/S

$.6 \times 100000 / 25000=2.4$

In this instance, the manager purchases two contracts valued at
$2 \times .65 \times 25000=32500$ (initial value of 2 contracts)

In July, the price of copper is 80 cents a pound so when the con-tracts are sold a profit of $\$ 7500$ is realized on the futures market.

$2 \times .80 \times 25000=40000$ (value of two contracts in July)

$40000-32500=7500$ (profit from futures market)

As seen earlier in September, 100000 pounds of wire cost $\$ 9750$ more than the cost of wire when the copper contracts were purchased. Using the $\$ 7500$ futures profits to offset the $\$ 9750$ price increase in wire, the wire costs the manager $\$ 110250$.

$9750-7500=2250$

$108000+2250=110250$ 
The Journal of Applied Business Research - Vol. 6, No. 1

Again it was impossible to attain a perfect hedge but most of the risk was shifted to a third party and the strategy only cost the company $\$ 2250$ instead of $\$ 9750$. Also note that if the price had dropped to 50 cents, the company would have made a $\$ 2250$ profit.

In the two preceding examples, the effect of time was very important. In the case of wire, the hedge was removed two months early reflecting the required two months for the price changes to work their way through the system.

This raises the question as to why the inventory control manager would want to use the futures market. Why not wait until July, and if the price of copper has risen to 80 cents a pound, go out on the market and purchase the required amount of copper wire before the price increases work their way through the system? The manager using the price of copper as a leading indicator could make purchases early if prices are rising and make them late if prices are falling. While such a policy might be appropriate for some companies, there are two situations under which such a policy would not be desirable.

1. The price of copper in July has risen to 80 cents a pound and when the manager goes out into the market to make wire purchases it is discovered that some of the price increase has worked its way through the system. While commodity prices change quickly, two or more months may be required for large price changes.

2. The manager may not have the warehousing or financing necessary to hold and make the needed wire purchases. Thus to go out and make the necessary wire purchases early would entail costs which would offset the price advantage of early purchase.

The most important significance of Example II is that the business using the hedging process did not directly use the raw materials being hedged but was a user of a product which required a high percentage of the raw material. Thus by making adjustments for time and the price change relationships, the futures markets can be used by a wide variety of manufacturers to shift risk to third parties and thereby stabilize the prices of their inputs.

\section{CONCLUSIONS}

Much has been written on models used to compute optimal order size and frequency to minimize inventory costs. Many of these models have been successfully applied by manufacturing companies for many years. While savings achieved through the application of these models can be significant, they overlook the effect of large and unpredictable price changes. When these changes occur, they can over shadow even the most efficient and effective inventory ordering policy. It was pointed out that improved forecasting will not always help because the price fluctuations often do not adhere to past price relationships. It is in this environment that hedging through the futures markets can be used by the manufacturer to guarantee a stable price environment over a reasonable period of time. Furthermore, the users of this tool do not have to be users of the product being hedged but can be users of materials which are composed of a large amount of the raw material being hedged. Such an operating strategy gives the inventory control models an opportunity to work.

While the advantages of hedging have been illustrated, it has also been demonstrated that it is, at times, impossible to remove all risk through hedging. Due to the manner in which futures contracts are marketed, the inability to shift risk increases as its application is moved up the manufacturing chain. While this is a limitation, the alternative of doing nothing is worse. Thus it has been shown that a wide range of manufacturers could profit from the use of commodity futures as a hedging tool.

\section{BIBLIOGRAPHY}

Anderson, David R., Dennis J. Sweeney, and Thomas A. Williams. An Introduction to Management Science, (4th ed). West Publishing Company, New York, 1985.

Figlewski, Stephen. Hedging with Financial Futures for Institutional Investors, Ballinger Publishing Company, Cambridge, MA, 1986.

Gold, Gerald. Modern Commodity Futures Trading, Commodity Research Bureau, New York, 1975.

Heironymus, Thomas A. Economics of Futures Trading, Commodity Research Bureau, New York, 1971. 